\title{
A DELAYED PRESENTATION OF RIGHT SIDED CONGENITAL DIAPHRAGMATIC HERNIA WITH RIGHT LOWER LOBE HYPOPLASIA
}

Allena Premkumar ${ }^{1}$, Namballa Usha Rani², Yellapu Gayatri ${ }^{3}$, Gorantla Sambasiva Rao ${ }^{4}$, Silla Monisha ${ }^{5}$

\section{HOW TO CITE THIS ARTICLE:}

Allena Premkumar, Namballa Usha Rani, Yellapu Gayatri, Gorantla Sambasiva Rao, Silla Monisha. "A Delayed Presentation of Right sided Congenital Diaphragmatic Hernia with Right Lower Lobe Hypoplasia". Journal of Evolution of Medical and Dental Sciences 2015; Vol. 4, Issue 36, May 04; Page: 6327-6331,

DOI: $10.14260 /$ jemds/2015/918

ABSTRACT: Congenital diaphragmatic hernia (CDH) occurs in 1 in 3000 live births and Bochdalek's variety is the commonest. Left sided diaphragmatic hernias are more common (85\%) than right sided (13\%). It commonly presents in neonatal period with acute respiratory distress. Delayed presentation of $\mathrm{CDH}$ is less common and majority have nonspecific respiratory and gastro intestinal symptoms. We present a case of delayed presentation of right sided CDH. Multi detector computed tomography (MDCT) with 3DR and volume rendering images confirmed Bochdalek hernia with liver, right kidney in a transverse lie and bowel inside the thorax and also hypoplasia of right lower lobe. The child underwent surgical correction successfully and repair of rent was done with prosthetic mesh. She is currently doing well.

KEYWORDS: Congenital diaphragmatic hernia, bochdalek hernia, delayed presentation, hypoplasia of lung.

INTRODUCTION: Congenital diaphragmatic hernia (CDH) is a congenital defect in the integrity of diaphragm resulting in herniation of abdominal contents into thoracic cavity. In addition to the primary mass effect of bowel or solid organ inside the thorax, secondary effect of pulmonary hypoplasia and associated pulmonary hypertension usually determine the outcome. It occurs in about 1 in every 2000-4000 live births. Bochdalek hernia is the commonest type of CDH and left side is most commonly affected. If the right side is affected other structural lung lesions like congenital pulmonary adenomatoid malformation (CPAM) or sequestration should be considered in differential diagnosis. $\mathrm{CDH}$ generally presents with respiratory distress in neonatal period. Late presentation of $\mathrm{CDH}$ is less common and may present with gastrointestinal or respiratory symptoms late in childhood. We present a right sided CDH of Bochdalek's variety in a 4 year old child.

CASE REPORT: A 4 year old female child was brought to the OP with the symptoms of cough, breathlessness and abdominal pain. There was no history of trauma or febrile illness. The child had a normal history of birth and did not have significant past illness. There was no history of consanguinity between the parents. On examination, child was mildly tachypnoeic with accessory muscle activity. She was afebrile and Spo2 was 94\% on room air. Examination of chest revealed absence of chest movements on right side with shift of trachea and apical impulse to opposite side. There was dullnote on percussion over right lower hemithorax and breath sounds were absent.

Further investigation like blood counts and blood chemistry were with in normal range. Chest x-ray showed multiple cystic lucencies in right mid and lower zones resembling bowel loops and mediastinal shift to opposite side. Normal silhoutte of liver in the abdomen was missing. A CECT chest was performed and it showed a posterior diaphragmatic hernia with herniation of colon, small bowel 


\section{CASE REPORT}

loops and right kidney which was in a transverse lie and in prevertebral location, displacing and compressing the esophagus. In addition right bronchus intermedius was found ending blindly without visual signs of segmental bronchii. A 3D shaded surface volume rendered images showed the same findings with better depiction. A diagnosis of right diaphragmatic hernia with hypoplasia of right lower lobe was made and the child was referred to higher institute where she underwent laparotomy. During the surgery, after replacing the hernial contents into abdominal cavity repair of rent in diaphragm was performed with polyethylene terephthalate mesh (Dacron) as most of the hemidiaphragm was lacking. Her post-operative period was uneventful and she was discharged on tenth day. She was followed up for the next 2 years and she was found to be doing well.

DISCUSSION: The Congenital Diaphragmatic Hernia is a developmental defect that allows abdominal viscera to herniate into chest. It was first described in 1679 by Lazarus Riverius who incidentally noted a CDH during an autopsy. In 1845, Victor Alexander Bochdalek from Prague described both right and left posterolateral $\mathrm{CDH}$ and it is referred as Bochdalek hernia. ${ }^{1}$

Bochdalek Hernia is the commonest type of $\mathrm{CDH}$, occurs in utero at approximately 6 weeks of gestation, followed by Morgagni hernia and Hiatus hernia. Left side bochdaleks is seen in $85 \%$ of cases, right side in $13 \%$ of cases and rest are bilateral.

When diaphragmatic defect is large, as in the present case, more number of abdominal contents will be herniated into corresponding hemithorax leading to more severe compression of lung which causes a decrease in the bronchial and pulmonary artery branching and muscular hypertrophy of pulmonary artery tree. It results in various degrees of pulmoanry hypoplasia and persistant pulmonary hypertension. Wiseman and Macpherson (1977) classified CDH into 4 groups. ${ }^{2}$ The present case belongs to Group 2, which is defined as visceral herniation occurring at the stage of distal bronchial branching, resulting in unilateral hypoplasia. When large, these hernias are associated with high mortality. Even with surgical correction, mortality is about $30 \%$.

The relative rarity of right sided $\mathrm{CDH}$ is due to earlier closure of pleuro peritoneal opening and to the protective effect of liver developing in septum transversum. Late presentation of CDH presenting outside neonatal period is called CDH with delayed presentation. The incidence of late presentation is $10-20 \%$ and they most commonly present within $1 \mathrm{yr}$ of age. ${ }^{3}$ Clinical presentation of late cases is different from the new born forms and it ranges from intermittent nonspecific symptoms to a life threatening acute event. The prognosis in these patients is more often determined by complications like strangulation of herniated bowel, gastric volvulus, mid gut volvulus, hypoplasia of left ventricle in left sided hernia and mediastinal shift with respiratory embarrassment.4

For those who present late in life, the important features include respiratory symptoms (43\%), Gastrointestinal symptoms (13\%) both (13\%) asymptomatic in $11 \% .^{5}$

A chest $x$ ray following the passage of a naso gastric tube and barium contrast follow through studies facilitate the diagnosis of $\mathrm{CDH} .{ }^{6}$ Computed tomography and liver spleen scintigraphy seem to be the best diagnostic options in children with right sided CDH. MDCT with 3 dimensional reconstruction and volume rendering images depicts the rent in diaphragm and features such as fluid filled bowel in the thorax, relative paucity of gas in the abdomen, presence of organs such as, liver, spleen, kidney etc., Inside the thorax. In a new born with X-ray chest showing cystic lesions in the thorax, the differential diagnosis includes CPAM, pulmonary sequestration and staphylococcal pneumatocoeles. 


\section{CASE REPORT}

PRENATAL DIAGNOSIS AND FETAL INTERVENTIONS: In developed countries, a high prenatal detection rate of CDH (59\%) has been reported, using 3D ultrasound scan. The gestational age at diagnosis was greater than 24 weeks in half of prenatally diagnosed cases. ${ }^{7}$ Fetal Endoscopic Tracheal Occlusion (FETO) procedures like endoscopic external tracheal occlusion and endoscopic endoluminal tracheal occlusion in order to improve lung growth have shown improved outcome in experimental studies. ${ }^{8}$ The main advantage of prenatal detection of $\mathrm{CDH}$ is that mother can be referred to a specialist center where they can be electively managed by neonatal/surgical teams.

POSTNATAL DIAGNOSIS AND MANAGEMENT: Postnatal resuscitation of CDH with acute respiratory distress is a surgical emergency. Recently the concept has changed to delay repair for atleast 24-48 hrs to allow for clinical stabilization and a fall in pulmonary vascular resistance. ${ }^{9}$ Stabilization is achieved with mechanical ventilation, paralysis, pulmonary vasodilators and Extra Corporeal Membrane oxygenation. After stabilization of the newborn repair of CDH is performed. A Transthoracic / abdominal approach / VATS technique are advocated.

Hernia repair is carried out when most of the hemidiaphragm is lacking, using a prosthetic mesh (Marlex / Gorotex / Dacron mesh). Peri operative care includes gentle ventilation to minimize lung injury, High Frequency Ventilation (HFV), Inhaled Nitric oxide therapy and Extra Corporeal Membrane oxygenation.

CONCLUSION: This case is presented because right sided diaphragmatic hernia is rare and delayed presentation is less common than neonatal presentation

Figure 1: Chest x ray showing multiple cystic lucencies on right side representing bowel loops and absence of normal silhouette of liver.

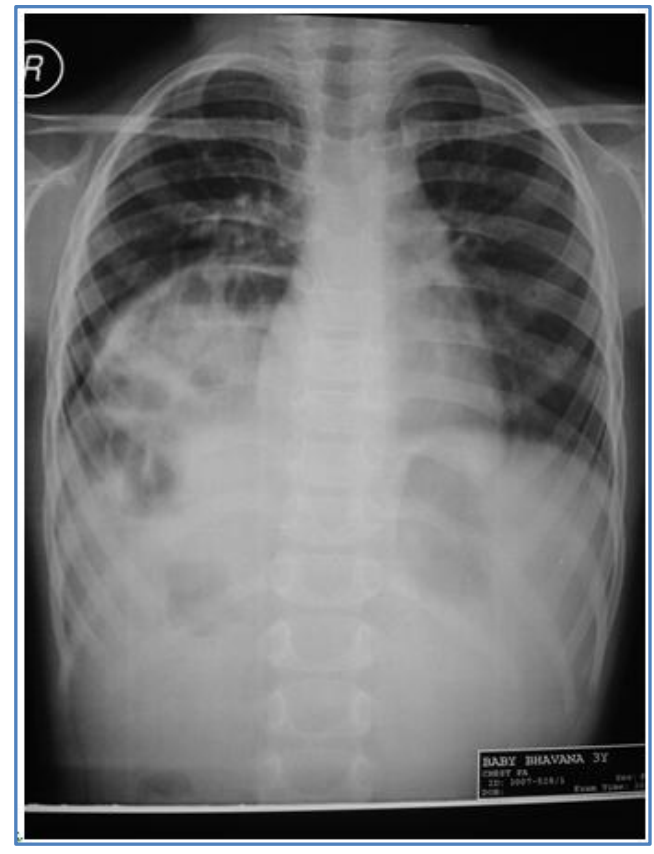

Fig. 1 


\section{CASE REPORT}

Figure 2: CECT thorax, axial section showing liver, bowel, and kidney in a transverse lie inside thorax.

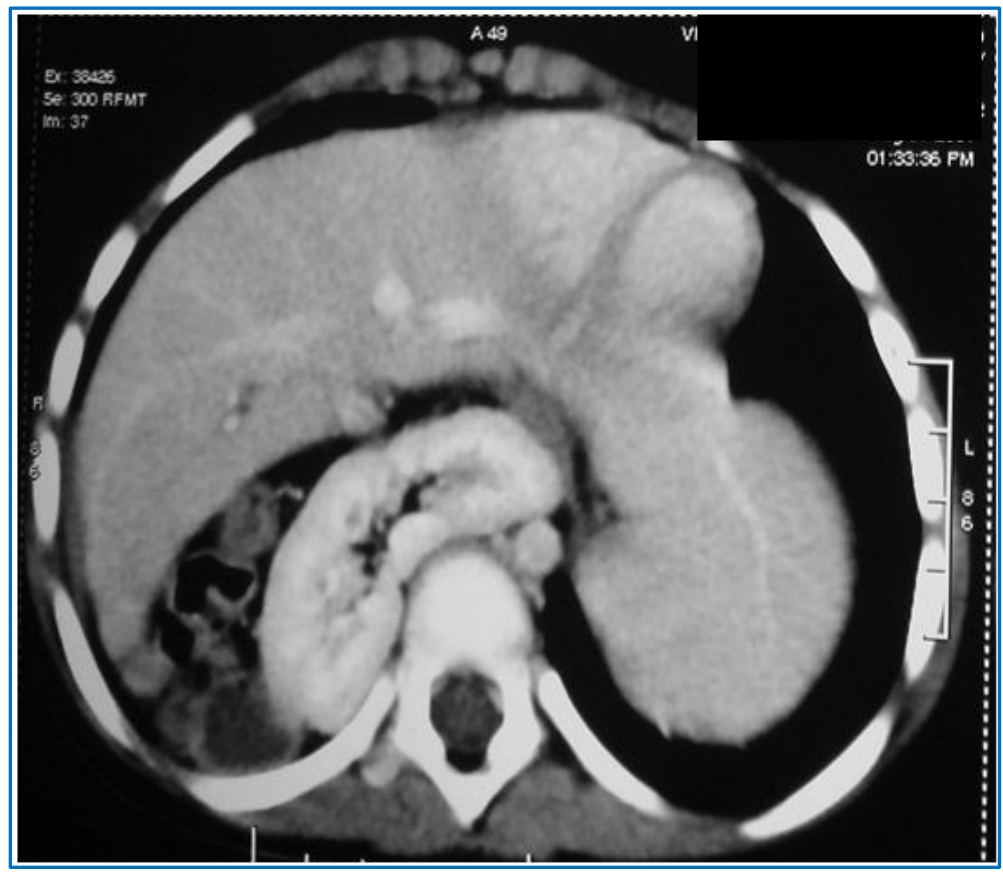

Fig. 2

Figure 3: MDCT with 3D shaded surface volume rendering images showing intermediate bronchus ending blindly.

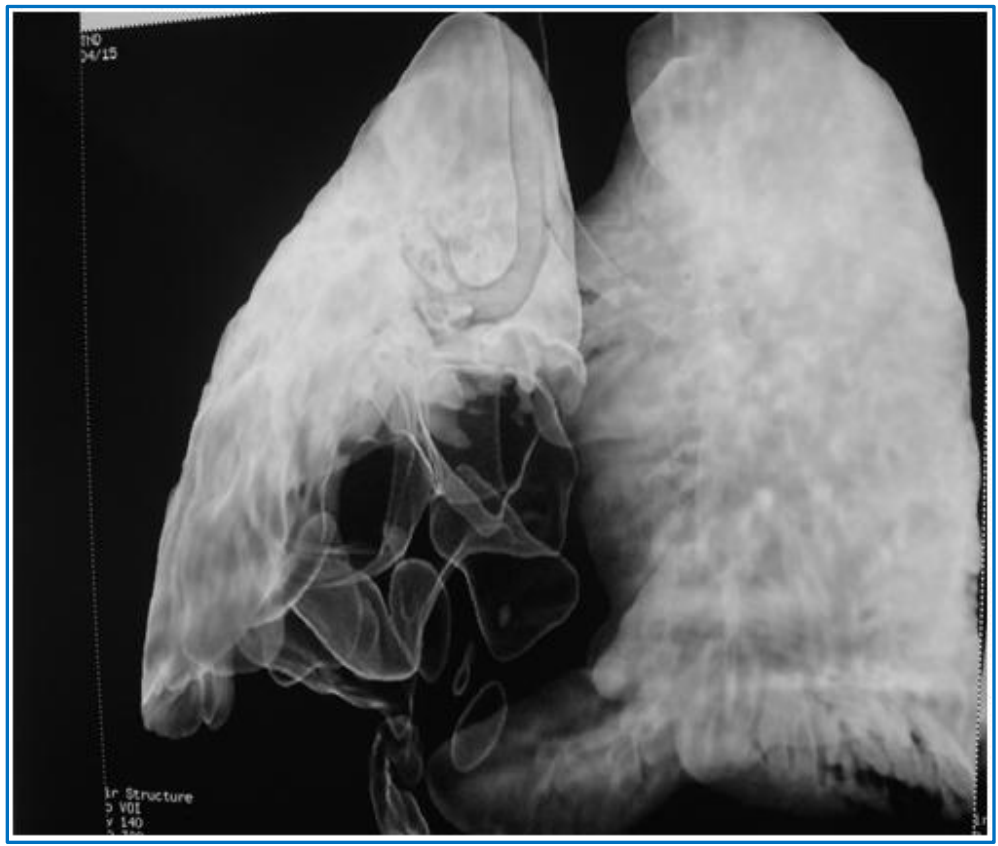

Fig. 3 


\section{REFERENCES:}

1. Hekmantia A, Mc Hugh K., Congenital Diaphragmatic Hernia: emedicine Radiology, Cardiac disease and Critical care 2008, 5-6.

2. Wiseman NE, Mac Pherson RI: Acquired Congenital Diaphragmatic Hernia. J Paediatric Surg 12: 657, 1977.

3. Berman L, Stringer D, Ein SH, Shardling B, The late presenting paediatric bochdalek hernia: a 20 year review: J Paediatric Surg 1988; 23 (8): 735-9.

4. Steinhorm RH. , Congenital Diaphragmatic Hernia, Cardiac Disease and critical care medicine, Neonatology 2009, 1-5.

5. M Mei-Zahav, M Solomon, D Trachsel and J. C. Langer, 'Bochdalek Diaphragmatic hernia: Not only a neonatal disease' Archives of Disease in Childhood. Vol 88, no. 6, pp532-535, 2003.

6. Baglaj M. Dorobisz U. Late presenting Congenital Diaphragmatic Hernia in Children: A literature review. Paediatric Radiol 2005; 35 (5): 478.

7. E. Garne, M Haeusler, I Baorisic, R. Gjergia, C Stoll and M. Clementi, " A Congenital diaphragmatic hernia: evaluation of prenatal diagnosis in 20 European regions" Ultrasound in Obstetrics and Gynaecology, Vol. 19, no. 4, pp329-333, 2002.

8. J. C Jani, K H Nicolarides, E. Gratacos et al, "Severe diaphragmatic Hernia treated by fetal endoscopic tracheal occlusion" Ultrasound in Obstetrics and Gynaecology, Vol. 34, no. 3, pp304310, 2009.

9. Emeka B, Kesiema and Chinenye N. Kesieme, 'Congenital Diaphragmatic Hernia: Review of current concept in surgical management' IS RN Surgery, Vol. 2011, Article 1 D 974041, pp1-8, 2011.

\section{AUTHORS: \\ 1. Allena Premkumar \\ 2. Namballa Usha Rani \\ 3. Yellapu Gayatri \\ 4. Gorantla Sambasiva Rao \\ 5. Silla Monisha}

\section{PARTICULARS OF CONTRIBUTORS:}

1. Professor, Department of Pulmonary Medicine, Andhra Medical College, Visakhapatnam.

2. Associate Professor, Department of Pulmonary Medicine, Andhra Medical College, Visakhapatnam.

3. Assistant Professor, Department of Pulmonary Medicine, Andhra Medical College, Visakhapatnam.

\section{FINANCIAL OR OTHER} COMPETING INTERESTS: None
4. Professor, Department of Pulmonary Medicine, Andhra Medical College, Visakhapatnam.

5. Senior Resident, Department of Pulmonary Medicine, Andhra Medical College, Visakhapatnam.

\section{NAME ADDRESS EMAIL ID OF THE CORRESPONDING AUTHOR:}

Dr. Silla Monisha, W/o. P. Ramkumar, Door No. 10-5-8, Flat No. 202, Swarna Soudha Apartment, Ram Nagar, Visakhapatnam. E-mail: monishasilla@gmail.com

Date of Submission: 10/04/2015. Date of Peer Review: 11/04/2015. Date of Acceptance: 24/04/2015. Date of Publishing: 04/05/2015. 